2015

\title{
Improving University Students' Perception of Mathematics and Mathematics Ability
}

Shelly L. Wismath

University of Lethbridge, wismaths@uleth.ca

Alyson Worrall

University of Lethbridge, alyson.worrall@uleth.ca

Follow this and additional works at: https://digitalcommons.usf.edu/numeracy

Part of the Higher Education Commons, Mathematics Commons, and the Science and Mathematics Education Commons

\section{Recommended Citation}

Wismath, Shelly L., and Alyson Worrall. "Improving University Students' Perception of Mathematics and Mathematics Ability." Numeracy 8, Iss. 1 (2015): Article 9. DOI: http://dx.doi.org/10.5038/1936-4660.8.1.9 


\title{
Improving University Students' Perception of Mathematics and Mathematics
}

\section{Ability}

\begin{abstract}
Although mathematical and quantitative reasoning skills are an essential part of adult life in our society, many students arrive at post-secondary education without such skills. Taking a standard mathematics course such as calculus may do little to improve those skills. Using a modification of the Tapia \& Marsh questionnaire, we surveyed 62 students taking a broad quantitative reasoning course designed to develop quantitative skills, with respect to two broad attitudinal areas: students' perception of their own ability, confidence and anxiety, and their perception of the value of mathematics in their studies and their lives. Pre- to post-course comparisons were done by both paired t-tests and Wilcoxon signed-rank tests. Our results showed a significant increase in confidence and decrease in anxiety, while perception of the value of mathematics was already high and changed little by the end of the course.
\end{abstract}

\section{Keywords}

mathematics, quantitative reasoning, value, confidence.

\section{Creative Commons License}

\section{(c) (i) (5)}

This work is licensed under a Creative Commons Attribution-Noncommercial 4.0 License

\section{Cover Page Footnote}

Shelly Wismath is a Professor of Mathematics at the University of Lethbridge, and for the last five years has also taught in the Liberal Education Program there. Her research interests are in abstract algebra, and in the teaching and learning of critical thinking skills and quantitative reasoning skills, especially for nonmath, non-science majors.

Alyson Worrall joined the Faculty of Education at the University of Lethbridge in 2007, after a successful career in teaching high school mathematics and earning a Ph.D. in teacher development from the University of Toronto. While at the University of Lethbridge, she taught mathematics methods courses to pre-service teachers. Her interest in research into math anxiety results from having observed some of her students' fearful responses to these courses. 


\section{Introduction}

Much attention has been given over recent decades to the teaching and learning of mathematics, and to the importance of mathematical and quantitative skills for students and indeed for all adults in our society. For students at the postsecondary level, mathematical skills form a strong prerequisite for success in many areas of science, technology and engineering; mathematical skills also serve as a critical filter (Sells 1978; Ma and Johnson 2008) for many other subjects and career areas. But outside of these disciplines, a certain level of mathematical or quantitative literacy is desirable for all adults. Cockcroft (1982: 10) first used the term "numeracy" for mathematical literacy, defining it as "the ability to cope confidently with the mathematical demands of adult life." A Statistics Canada Policy Research Initiative, the Adult Literacy and Lifeskills (ALL) Survey, described quantitative literacy as "the knowledge and skills required to effectively manage and respond to the mathematical demands of diverse situations" (Murray et al. 2005: 142). Simpson (1999: 2) stressed the need for quantitative literacy to "prepare graduates to function well as citizens in modern society."

Despite the importance of developing quantitative literacy skills, many students avoid mathematics or quantitative courses at the secondary or postsecondary levels. There is a rich literature on math anxiety, defined by Richardson and Suinn (1972: 551) as "a feeling of tension and anxiety that interferes with the manipulation of numbers and the solving of mathematical problems in a wide variety of ordinary life and academic situations," and by Ashcraft and Moore (2009) as a negative affective or emotional reaction to numbers, math, and mathematics calculations which leads to avoidance of mathematics. Math anxiety has been shown to be related to many affective and educational factors (Hembree 1990; Ma 1999). It is correlated with test anxiety (Ashcraft 2002), but inversely related to performance on standardized tests and high school grades and to numerical skills at various levels (Ashcraft and Faust 1994; Ashcraft and Kirk 2001; Faust et al. 1 996; Maloney, Ansari and Fugelsang 2010; Maloney, Risko, Ansari and Fugelsang 2010; Moore and Ashcraft 2012). Math anxiety is also inversely related to desirable attitudes towards mathematics such as self-confidence, self-efficacy, enjoyment, motivation, and value.

Given the impact of student attitudes and beliefs about mathematics on their motivation and performance, it is necessary to be able to measure such attitudes. The widely used Fennema-Sherman Mathematics Attitude Scales (Fennema and Sherman 1976), which was developed for secondary students, measured nine aspects of attitude. The Attitudes Toward Mathematics Inventory, created by Tapia and Marsh (2004), focused on six factors: confidence, anxiety, value, 
enjoyment, motivation, and parent/teacher expectations.

The confidence factor measures students' confidence and self-efficacy in approaching mathematical tasks, and belief in their ability to successfully complete these tasks (Kalder and Lesik 2001). Bandura (1995: 2) defined selfefficacy as "the belief in one's capabilities to organize and execute the courses of action required to manage prospective situations." Various authors have shown an important correlation between self-efficacy and student achievement (Bandura et al. 1996; Liu et al. 2006) and mathematics achievement (Stevens et al. 2004). There is also an important gender component to self-efficacy. Zeldin and Pajares (2000) argued that confidence and self-efficacy are particularly key factors for whether female students enter into or remain in science or math programs and careers. They noted "women aptly competent in mathematics often fail to pursue mathematics-related careers because they have low self-efficacy perceptions about their competence" (Zeldin and Pajares 2000: 218). Sadker and Sadker (1994) referred to the gender differences in belief in math and science abilities as a "confidence gap". There is of course a rich literature on the role of gender in mathematics, and there have been decades of efforts to improve the participation rates and success of female students in mathematics (American Association of University Women 2008; Corbett et al. 2008; Fennema 1989; Leder et al. 1999; Schiebinger 2001; Taylor et al. 1996).

The anxiety category in the Tapia and Marsh instrument considers the level of students' anxiety about mathematics and how that anxiety might affect their performance on mathematical tasks. The value factor looks at whether students see the importance and relevance of mathematics to their present and future work. Kilpatrick et al. (2001) described a model of mathematical proficiency having five intertwined strands: procedural fluency, conceptual understanding, adaptive reasoning, strategic competence, and productive disposition. The last strand, productive disposition, is a combination of the three Tapia and Marsh factors discussed here, confidence, anxiety and value. It is defined as the "habitual inclination to see mathematics as sensible, useful, and worthwhile, coupled with a belief in diligence and one's own efficacy" (Kilpatrick et al. 2001: 5). Madison and Dingman (2010) argued that this is the weakest of the five strands of mathematical proficiency for quantitative reasoning students.

From a pedagogical point of view, there is a distinction at the post-secondary level of education between mathematics and quantitative reasoning (QR). While the two are certainly strongly connected, Davidson and McKinney (2001) pointed out that mathematics is primarily an academic discipline, while $\mathrm{QR}$ refers to practical skills. That is, QR refers to those parts of mathematics needed to be a functioning consumer and citizen in a technological society. They wrote "few people are trained to work with complex mathematical concepts, but all educated citizens should be able to understand mathematics well enough to develop 
informed opinions about quantitative concepts" (Davidson and McKinney 2001: 1). The traditional college or university mathematics curriculum that begins with a sequence of calculus and linear algebra courses serves the needs of mathematics and other science majors, but it does not serve the needs of other students for QR skills. Agustin et al. (2012) presented empirical evidence that "taking one or more traditional math courses does not necessarily develop quantitative reasoning" (p. 312). There is a need, therefore, for courses specifically designed to address QR skills for non-math and non-science majors. The various aspects of student attitude towards mathematics are equally important for traditional mathematics and for quantitative reasoning. Our research investigates whether taking a quantitative literacy course can cause significant improvements in university students' attitudes towards mathematics, specifically in the productive-disposition aspects of confidence, anxiety and value.

At the university at which we teach, all undergraduate students are required to take at least four courses from a list of Science-designated courses. Many students in non-science majors find this requirement intimidating, as they do not have the background knowledge in mathematics to take most of the designated courses and often are nervous about taking any mathematics courses. The study reported on here involves a Quantitative Reasoning course specifically planned to meet the quantitative literacy needs of such students (Mackay and Wismath 2012). It is taken mainly by students in non-math, non-science majors to fulfill their science requirements, as well as by those who want to improve their mathematics background in preparation for other courses or future career choices. A small proportion of students in the course are math or science majors who are comfortable with the subject matter. Generally, close to half of the students are in or plan to apply to the university's Faculty of Education to train as K-12 teachers.

\section{The QR Course}

There are many models of university-level mathematics courses for nonmathematics majors, from remedial courses to statistics courses for social sciences, to "math for poets" courses or "great ideas" courses. The model used for the course we describe here was carefully chosen to facilitate students' understanding of and enjoyment and confidence in mathematics. Because the course is offered within the Liberal Education Program rather than in the mathematics department, every effort was made to relate the topics discussed to a broad range of disciplinary areas. The course begins with a study of the history of number systems, from Babylonian and Egyptian to the modern Hindu-Arabic system; this provides a non-threatening, non-technical introduction to the study of numbers, in order to deepen student understanding of our base-ten place-value number system. This topic leads to a discussion of negative, rational and irrational 
numbers, and the properties of these various sets of numbers. This foundation then leads to the study of large and small numbers, scientific notation and percentages. The latter leads to a study of savings and loans and compound interest, which is then used to motivate a study of models, graphs, and functions, and of linear and exponential growth models. As time permits, we also consider critical analysis of statistical studies (Bennett and Briggs 2005). Students typically find the historical and financial parts of the course the most interesting, and they find the financial studies the most relevant to their lives. No textbook is required for the course, but the choice of topics has been influenced by Bennett and Briggs (2005).

Our choice of topics has been combined with a pedagogical approach focused on enabling students to do mathematics and building their confidence. Class time is used to discuss math anxiety (Richardson and Suinn 1972) and strategies to succeed in mathematics-based study. New topics are introduced with examples, and frequent opportunities are given in class for students to work on exercises in small groups. In addition to the three hours per week of regular classes, there is an optional, weekly, 50-minute tutorial session, run by an undergraduate teaching assistant who is usually a mathematics education major; the tutorial allows students to ask questions about anything they didn't understand in class and to work on their homework assignments with friendly and approachable help at hand. Assessment in the course is done via weekly assignments and three term tests; the pattern is a test after every three assignments. This gives students ample practice along with quick feedback on how they are doing on each topic.

\section{Methodology}

In 2012, we conducted a study to investigate whether taking a general quantitative reasoning course affected the attitudes of university students with respect to confidence with, anxiety about, and the perceived value of mathematics. Our study participants were students who enrolled in the quantitative reasoning course, over two semesters, January and September of 2012. Of the total enrollment of 100 students, 73 students consented to participate in the study, and we were able to collect complete data for 62 of them. Appropriate human studies research ethics approval was obtained, and all efforts were made to preserve confidentiality of student responses; in particular, no data were shared with the course instructor until the course was completed and all grades submitted.

Our main instrument was a questionnaire designed to measure the various attitudinal factors identified above regarding mathematics. The questionnaire, adapted from the instrument developed by Tapia and Marsh (2004), asked students to respond on a five-point Likert scale to 26 items regarding various aspects of their comfort level with mathematics and their perception of the 
importance or relevance of mathematics (see Appendix 1). A few items also considered motivation and enjoyment of mathematics, but we did not include any aspect of parent or teacher expectations in our study. The questionnaire was given at the beginning and again at the end of the course.

We also collected basic demographic information from the participants, and information about their thinking (Barsch 1991) and learning (Gregorc 1979) styles. We were interested in analyzing any changes in attitude with respect to various factors which may be significant in math perception and anxiety, factors such as gender, major (math/science versus non- math/science, or education majors versus non-education majors), thinking styles, learning styles, and year of study. Finally, participants completed a short self-reflection survey at the end of the course.

At the same time, we also administered these instruments to students enrolled in a mathematics curriculum methods course for non-math majors in the Faculty of Education. The enrollment in this course was unusually low in 2012, and it provided an insufficient sample size for analysis. Consequently, the data collected from those students were removed before the remaining data were analyzed.

For the quantitative survey data collected, we ran two sets of tests. First, paired t-tests were done for each survey item, comparing the pre- and post-course results. Because paired t-tests are not always suitable for Likert-scale data, we also ran a Wilcoxon signed-rank test for each item, again comparing pre- and post-course data. Both sets of tests were run on an SPSS package, using a significance level of 0.05 . We also ran cross-tabs for survey results with the factors of thinking style, learning style, gender and major area, again using a significance level of 0.05 .

\section{Results}

\section{Changes in Confidence and Anxiety Measures}

Fourteen of the 26 questions in our attitude survey asked students to rate their own confidence in or anxiety about their ability to do well in mathematics courses. Of these, we found a significant change (at alpha $=0.05)$ in nine items on both the paired t-tests and the Wilcoxon signed-rank tests used to compare pre- to post-course test responses (Table 1). Questions 1, 2 and 5 showed statistically significant decreases in areas that speak to math anxiety and insecurity, and Questions 7 and 8 showed significant increases in confidence factors.

Although we used a significance level of alpha $=0.05$, it can be argued that when analyzing multiple data items like we have done here, a lower significance level should be used. However, it should be noted from Table 1 that Item 3, "Studying mathematics poses no problems for me" had the highest p-values on both tests, at 0.030 and 0.032 , while the p-values on the other eight items were all 
close to if not less than 0.01 . We argue that these results provide strong evidence of significant change.

Table 1

Survey Items Regarding Comfort Level with Mathematics.

\begin{tabular}{|c|c|c|c|c|c|}
\hline Question & Pre-av. & Post- av. & Diff. in av. & $\begin{array}{c}\text { T-test } \\
\text { p-value }\end{array}$ & $\begin{array}{l}\text { Wilcoxon } \\
\text { p-value }\end{array}$ \\
\hline 1. Mathematics classes are stressful for me. & 3.42 & 3.11 & -.31 & 0.011 & 0.012 \\
\hline $\begin{array}{l}\text { 2. I'm one of those people who just doesn't } \\
\text { understand mathematics. }\end{array}$ & 2.79 & 2.52 & -.27 & 0.010 & 0.010 \\
\hline $\begin{array}{l}\text { 3. Studying mathematics poses no problem } \\
\text { for me. }\end{array}$ & 2.60 & 2.82 & .22 & 0.030 & 0.032 \\
\hline $\begin{array}{l}\text { 5. Whenever I am given a mathematics } \\
\text { question to do, I do not know how to get } \\
\text { started. }\end{array}$ & 2.93 & 2.54 & -.39 & $<0.001$ & 0.001 \\
\hline $\begin{array}{l}\text { 7. I am proud of my abilities in } \\
\text { mathematics. }\end{array}$ & 2.69 & 3.08 & .39 & $<0.001$ & $<0.0001$ \\
\hline $\begin{array}{l}\text { 8. I never do well academically in a } \\
\text { mathematics course. }\end{array}$ & 2.71 & 2.31 & -.40 & 0.001 & 0.001 \\
\hline $\begin{array}{l}\text { 17. Mathematics class is the most enjoyable } \\
\text { class in my timetable. }\end{array}$ & 2.16 & 2.85 & .69 & $<0.001$ & $<0.0001$ \\
\hline $\begin{array}{l}\text { 18. Mathematics is something to be endured } \\
\text { rather than enjoyed. }\end{array}$ & 2.95 & 2.52 & -.43 & 0.001 & 0.002 \\
\hline $\begin{array}{l}\text { 21. I enjoy explaining mathematics to } \\
\text { others. }\end{array}$ & 2.37 & 2.98 & .61 & $<0.001$ & $<0.0001$ \\
\hline
\end{tabular}

Further analysis was conducted on several of these nine items in order to include the impact of having respondents (e.g., some math majors) in the study who were already quite confident with mathematics. For example, Question 7, "I am proud of my abilities in mathematics," initially had 18 (29\%) respondents select either Agree or Strongly Agree. When this group was excluded from the data, a paired t-test for pre- to post-course scores on this item still showed a significant change: the average went from 2.06 to 2.88 , still with a p-value of $<0.0001$. This result gives additional support to the argument that student confidence did increase over the duration of the study. Similarly, a paired pre- to post-course t-test on Question 1, "math classes are often stressful to me," omitting the $26 \%$ of respondents who initially selected Disagree or Strongly Disagree, showed a shift from an average of 4.0 to 3.0, again at a p-value of $<0.0001$.

\section{Changes in Perception of the Value of Mathematics}

Ten items on the attitude survey looked at students' perception of the importance or relevance of mathematics. Of these, the same three items were flagged by both the paired t-tests and the Wilcoxon signed-rank tests comparing pre- to postcourse test responses. These items, with the respective p-values for the two tests, are shown in Table 2. Additionally, two other survey items questioned students' willingness to take further mathematics electives or to recommend such courses to their friends. Both of these questions might plausibly be interpreted as 
contributing to the perceived importance of mathematics. Table 3 shows the data for these two questions.

Table 2

Survey Items Regarding Attitude Towards Subject of Mathematics

\begin{tabular}{lccccc}
\hline Question & Pre- av. & Post- av. & Diff. in av. & $\begin{array}{l}\text { T-test } \\
\text { p-value }\end{array}$ & $\begin{array}{l}\text { Wilcoxon } \\
\text { p-value }\end{array}$ \\
\hline $\begin{array}{l}\text { 12. Understanding mathematics is not really } \\
\text { required once a person leaves school. }\end{array}$ & 1.60 & 1.42 & -.18 & 0.033 & 0.034 \\
$\begin{array}{l}\text { 14. Mathematics is merely a set of rules \& } \\
\text { procedures that need to be memorized. }\end{array}$ & 2.73 & 2.23 & -.50 & 0.001 & 0.001 \\
$\begin{array}{l}\text { 15. Mathematics classes are interesting \& } \\
\text { intellectually stimulating. }\end{array}$ & 2.93 & 3.41 & .48 & 0.001 & 0.001 \\
\hline
\end{tabular}

Table 3

Survey Items on Willingness to Take or Recommend Mathematics Elective courses

\begin{tabular}{lccccc}
\hline Question & Pre- av. & Post.av. & Diff. in av. & $\begin{array}{c}\text { T-Test } \\
\text { p-value }\end{array}$ & $\begin{array}{c}\text { Wilcoxon } \\
\text { p-value }\end{array}$ \\
\hline $\begin{array}{l}\text { 23. I would take math courses as electives in } \\
\text { my program. }\end{array}$ & 2.81 & 3.08 & .27 & 0.043 & $>0.05$ \\
$\begin{array}{l}\text { 25. I would recommend taking math courses } \\
\text { to my friends. }\end{array}$ & 2.97 & 3.58 & .61 & $<0.001$ & $<0.0001$ \\
\hline
\end{tabular}

There were four other survey items regarding the importance of mathematics. Three of them were: "Mathematics is used by most people every day," "Knowledge of mathematics is important to future success in life," and "Having a background in mathematics will be useful regardless of whether I use it directly in the future or not." On both the pre- and post-course administrations of the survey, these items showed an average response of 4.4 each, indicating that our students did in fact already believe that math was important and useful, although they were not confident in their own abilities. Each of these questions showed very slight, but not statistically significant, changes. The fourth item, "Other than Science, mathematics is unrelated to any other subject area" similarly showed an average of 1.6 both pre- and post-course surveys, indicating that students felt fairly strongly that math is important even for students outside the science disciplines.

\section{Gender as a Factor}

Gender has long been studied as an important factor in mathematics ability, performance, and motivation, with special attention to math anxiety (Taylor et al. 1996; Leder et al. 1999; Schiebinger 2001; American Association of University Women 2008). Of the 62 participants in our study, 45 (72.58\%) were female and $17(27.42 \%)$ were male, a split which is representative of the gender split in the course. Cross-tabulations were run using gender and the attitude survey items to 
see if gender appeared as a factor in any of the items. Interestingly, most items showed no significant gender differences. But three items, all related to confidence and anxiety, resulted in a p-value of 0.05 or less on a Pearson ChiSquared test. On the pretest, the item "Mathematics is something to be endured rather than enjoyed" had a p-value of 0.043 . On the post-test, "Whenever I am given a mathematics question to do, I do not know how to get started" had a pvalue of 0.036 , while "I often admit to people that I am not good at mathematics" had a p-value of 0.030 . Table 4 shows the differences in response, broken down by gender, for these three questions from pre- to post-test data.

Table 4

Gender Breakdown on Items Identified in Factor Analysis

\begin{tabular}{lccccc}
\hline Question & Gender & Pre- av. & Post- av. & $\begin{array}{c}\text { Diff. in } \\
\text { average }\end{array}$ & $\begin{array}{c}\text { T-test } \\
\text { p-value }\end{array}$ \\
\hline 5. Whenever I am given a & Female & 3.00 & 2.58 & -.42 & 0.002 \\
mathematics question to do, I do & Male & 2.75 & 2.44 & -.31 & 0.096 \\
not know how to get started. & Female & 3.24 & 2.96 & -.28 & 0.096 \\
6. I often admit to people that I & Male & 3.12 & 3.29 & .17 & 0.579 \\
am not good at mathematics. & Female & 2.93 & 2.56 & -.37 & 0.018 \\
18. Mathematics is something to & Male & 3.00 & 2.41 & -.59 & 0.028 \\
be endured rather than enjoyed. & & & & &
\end{tabular}

\section{Area of Study as a Factor}

Participants in the study were asked to indicate their major area of study, and their answers were coded into three categories: fine arts, math/sciences, or humanities and social sciences. There were six participants (9.7\%) in fine arts, and 18 (29.0\%) in math/sciences, with the majority, 38 (61.29\%), in humanities or social science subjects. As might be expected, area of study was a significant factor for responses to numerous survey items. Five survey items were flagged by p-values of 0.05 or less on Pearson Chi-Squared cross-tabulations with major area: items 1 , $2,3,15$ and 24 . The first three items, all with p-values $<0.01$, warranted further investigation as indicators of math anxiety. Since being in math or science was expected to indicate less anxiety, we considered two groups of students: $n=18$ in math or science, and $n=44$ in arts, humanities and social sciences. Table 5 shows the change from pre- to post-course test response for each of these groups on the three survey items. For space reasons, the two groups are denoted in the table by "Math/Sci" and "Other." It is clear that the Math/Sci group experienced little if any overall change on these items from pre-course test to post-course test, while the "other" group did show significant change even at an alpha level of 0.01 .

We were particularly interested in any changes among our participants who were prospective teachers, as teachers' attitudes are known to affect student performance and attitudes (Kalder and Lesik 2001). Although we did not 
specifically ask participants their career plans (other than their major), 26 people (41.9\%) did identify themselves as being in the Faculty of Education or planning to apply to it. We ran separate t-tests on all survey items for this smaller group to see if their responses differed from the larger group. The paired t-tests indicated statistically significant change, at an alpha-level of 0.05 , from pre- to post-course administration on 12 of the survey items. Of these, 11 were items already discussed in Tables 1, 2 and 3 above (items 1, 2, 5, 7, 8, 14, 15, 17, 18, 21, and 25). Three items, which showed significant change for the general group, did not for this smaller group: survey items 3,12 and 23; we do not know why this occurred, and a follow-up on these questions would be interesting to pursue. Finally item 16, "Mathematics requires no creativity" showed a significant decrease in the smaller group but not in the larger group.

Table 5:

Area of Study Breakdown on Items Identified by Factor Analysis

\begin{tabular}{llcccc}
\hline Question & $\begin{array}{l}\text { Major } \\
\text { Area }\end{array}$ & Pre- av. & Post- av. & $\begin{array}{c}\text { Diff. in } \\
\text { average }\end{array}$ & $\begin{array}{c}\text { T-test } \\
\text { P-value }\end{array}$ \\
\hline 1. Mathematics classes are & Math/Sci. & 2.50 & 2.44 & -.06 & 0.334 \\
stressful for me. & Other & 3.795 & 3.386 & -.409 & 0.005 \\
$\begin{array}{l}\text { 2. I'm one of those people who } \\
\text { just doesn't understand }\end{array}$ & Math/Sci. & 1.89 & 1.89 & 0.000 & 0.500 \\
mathematics. & Other & 3.159 & 2.773 & -.386 & 0.003 \\
$\begin{array}{l}\text { 3. Studying mathematics poses } \\
\text { no problems for me. }\end{array}$ & Math/Sci. & 3.56 & 3.56 & 0.000 & 0.500 \\
& Other & 2.205 & 2.523 & .319 & 0.006 \\
\hline
\end{tabular}

\section{Thinking and Learning Styles}

Each study participant filled in questionnaires to determine their learning style (visual, auditory, tactile; Gregorc 1979) and their thinking style (concrete or abstract, sequential or random; Barsch 1991). We found no significant effect of these factors on response to any of the survey items in either the whole group or the smaller education group. The diversity of majors in the participants was also evident in the diversity in thinking and learning styles, but no patterns appeared to connect such styles with mathematics attitudes.

\section{Final Survey Data}

When the post-course version of the questionnaire was administered, students were also asked to respond to several short-answer questions. The first of these asked, "Would you recommend to other students, who may be anxious about enrolling in a mathematics course, that they take this course? Why or why not?" Ninety-five percent of respondents answered "yes" to this question, many of them quite enthusiastically (for example, "Yes!!" "would highly recommend," "absolutely," "definitely"). Five people mentioned the value of real or practical applications, while ten specifically mentioned the financial math chapter as being 
very helpful to them. The following written responses show an increase in positive attitudes with respect to both confidence in and value of mathematics.

Absolutely, taking this course helped me so much to understand that math can be interesting and fun.

As a person who never did well in math in high school I have done well in this class and learned the most usable information from this course than any other.

I would recommend this class because it approaches math in a way that everyone can understand. It demonstrates how often you use math in your daily lives and it is crucial that everyone can understand these concepts.

I recommend this course to EVERYONE I talk to. This is my favourite class, an amazing experience. I very much enjoyed this class and felt much more confident.

A second, short-answer question asked students whether they felt that their confidence in their mathematical abilities had changed over the duration of the course. Five students $(8.1 \%)$ did not answer the question, and nine students $(14.5 \%)$ indicated no change in their confidence. Of these nine, four specifically indicated that their confidence had already been high (several were math majors), and one said "no change, but it kind of made me want to teach math."

Forty-eight students, or $77.4 \%$ of respondents, indicated that their confidence had increased, supporting the quantitative data reported above. Their comments included the following:

My confidence in math is so much higher. Math is my friend now, not my enemy. I enjoy

doing math ... It is actually fun and the only class I looked forward to going to because it never got boring!

I am more confident now, and being that I am in the Ed Faculty [prospective teacher] I'd be much more confident teaching math if need be.

I'm more confident when facing a math problem, before I would avoid it and I now enjoy the straightforwardness of math.

I'm way more confident in math, I'll even bring up math related questions now when hanging out with my friends.

Finally, respondents were asked if they believed their impressions of the importance or relevance of mathematics had changed.

I realize now that math is a part of our everyday lives and we could not live without knowing it.

I definitely see now how important math is - you need to know it no matter what path you take in life.

One of the math majors wrote that "I appreciate all the 'real world' applications for math that were presented in this class and I have logged away some of the tricks and explanations for my own teaching career." Another math student wrote:

I think these liberal education math classes should be a requirement for every major. It 
may be more simple math but it is math that is applicable to real life, which is not always the case in other classes. ... They remind me why I love math and why I am a math major in the first place. That feeling is lost when you hit the high level math classes, you start to question that. These classes show why math is fun and important, and I wish more people would be less afraid of math and instead harness it as a tool.

\section{Discussion}

Although there is extensive literature outlining the effects of mathematics anxiety and low self-efficacy on mathematics performance and participation in mathematics courses, there is little research available to examine whether these limitations can be ameliorated through courses specifically designed to address them. Our key question, then, was whether a general course in quantitative reasoning would provide the necessary skills to allow students who suffer from math anxiety and who perceive themselves as lacking the ability to be successful in mathematics to overcome these obstacles. In particular, we wanted to know if such a course could change students' attitudes towards mathematics, particularly with respect to math anxiety and confidence and the perceived value of mathematics. While anecdotal evidence from end-of-term course evaluations, which are routinely carried out in courses across the campus, indicated that many students in the QR course experienced a lowering of anxiety and an increase in confidence regarding mathematics, we had no quantitative measurement for this. This study was constructed in order to gauge whether informal conclusions based on the qualitative data made up of students' positive comments about the course could be supported quantitatively.

Our results have shown changes in multiple dimensions after a one-semester course. The changes in attitude regarding the value of math were slight, because such attitudes were quite positive to start. The students who chose to register in the course already displayed a strong understanding of the value of quantitative skills and a willingness to work on their own quantitative skills. The most striking results occurred in the increased confidence and decreased anxiety exhibited at the end of the course. Our data analysis showed that the effect we suspected the QR course was having on these two areas, based on the students' end of course comments, was present and statistically significant.

Gender was not a significant factor in the study though we had thought it might be given the volume of research devoted to gender issues in mathematics. In addition, other areas which we thought, prior to the study, might be of significance were not borne out by the analysis of the data. This is particularly true of the thinking and learning styles. We wondered if any one particular style would dominate among the participants. There is a tendency to view people with strong mathematical ability as being particularly linear and concrete in thinking styles. We conjectured that students enrolled in the QR course who held a 
negative attitude toward mathematics would populate the Abstract quadrants in the Barsch (1979) inventory. This hypothesis was not supported by the data as there was no significant relationship between thinking styles and mathematical attitudes. The outcome of this finding is that math anxiety and low confidence levels in mathematics occur across all learning and thinking styles. These attitudes cannot be predicted by these means.

As noted previously, the QR course is an elective course taken predominantly by non-math majors to fulfill the four-course science requirement for all undergraduate degrees. Some math majors also take it as an elective course to further their own understanding of mathematics and to satisfy their curiosity about topics not found in traditional undergraduate mathematics courses. Consequently, attitudes towards mathematics did correlate with the participants' majors. Students who were enrolled in sciences predictably had more positive perceptions about their abilities in mathematics than those enrolled in non-science, non-math programs. This result was expected and supported by the data. If we were to repeat this study, we would be more specific in asking about majors and/or future plans for study. The information regarding some students' intent to enter the Faculty of Education or the current registration of some students in that Faculty was not actively sought, although it was of interest to us. Had the enrollments in the Faculty of Education course that was originally part of this study been high enough to be of statistical significance for the data collected to be included, we would have had the opportunity to make a specific examination of possible differences in attitudes towards mathematics between education and noneducation major students.

The qualitative comments made by students in the post-study survey closely match those made in the routine end-of-term course evaluations for the QR course prior to the beginning of this investigation. The major difference between the value of the former is that the self-reported changes in attitude can now be supported by quantitative data.

This study has limitations in that it represents a very short-term collection of data from a relatively small sample of students. We have no long-term data to suggest that participation in the QR course has a lasting effect on attitudes toward and confidence about mathematics by non-math majors. This is an area that would be a good avenue for future research. We have shown in a small sample that a course focused on lowering math anxiety and increasing confidence in mathematics can be successful in accomplishing those aims. The next steps would be to follow up with the participants to determine whether these are permanent or temporary changes. Another area of concern is that, although our study showed more positive changes than those found by Agustin et al (2012) from a traditional college mathematics course, we did not do any direct comparison. A future study comparing different models of QR courses with traditional math courses as well 
as standard introductory statistics courses would be optimal to provide evidence for the success of QR courses. Nevertheless, our study is a first step in providing such evidence.

\section{Conclusions}

Although strong quantitative reasoning skills are crucial for informed citizenship and participation in the adult world (Mathematics Association of America 2014), empirical data from Agustin et al. (2012) have shown that "taking one or more traditional math courses does not necessarily develop quantitative reasoning" (p. 312). We believe that it is important to assist our students to develop these skills as they move beyond their postsecondary education. In particular, students intending to become teachers are especially in need of QR skills, as many who teach within elementary schools will find themselves teaching mathematics at some point, regardless of their major. Instruction by teachers who have math anxiety and low mathematics self-efficacy has a high potential for passing on these traits to future generations of students; it is important to break this cycle.

\section{References}

American Association of University Women. 2008. Women and girls in STEM. Washington, DC.

Ashcraft, M. H. 2002. Math anxiety: Personal, educational and cognitive Consequences. Current Directions in Psychological Science 11(5): 181-185. http://dx.doi.org/10.1111/1467-8721.00196

and A. M. Moore. 2009. Mathematics anxiety and the affective drop in performance. Journal of Psychoeducational Assessment 27(3): 197-205. http://dx.doi.org/10.1177/0734282908330580

Ashcraft, M. H. and M. W. Faust. 1994. Mathematics anxiety and mental arithmetic performance: An exploratory investigation. Cognition and Emotion 8: 97-125. http://dx.doi.org/10.1080/02699939408408931

Ashcraft, M. H. and E. P. Kirk. 2001. The relationships among working memory, math anxiety, and performance. Journal of Experimental Psychology: General 130: 224-237. http://dx.doi.org/10.1037/0096-3445.130.2.224

Agustin, M. Z., M. Agustin, P. Brunkow, and S.Thomas. 2012. Developing quantitative reasoning: Will taking traditional math courses suffice? An empirical study. Journal of General Education 61(4): 305-313. http://dx.doi.org/10.1353/jge.2012.0037

Bandura, A. 1995. Self-efficacy in changing societies. New York: Cambridge University Press. http://dx.doi.org/10.1017/CBO9780511527692

_, C. Barbaranelli, G. V. Caprara, and C. Pastorelli. 1996. Multifaceted 
impact of self-efficacy beliefs on academic functioning. Child Development 67(3): 1206-1222. http://dx.doi.org/10.2307/1131888

Barsch, J. 1991. Barsch learning style inventory. Novato, CA: Academic Therapy. Bennett, J.O., and W. L. Briggs, 2005. Using and understanding Mathematics: A quantitative reasoning approach. 3rd Ed. Reading, MA: Pearson/Addison Wesley Publishers.

Cockcroft, W. 1982. Mathematics counts: Report of the Committee of Inquiry into the teaching of mathematics in schools. London: HMSO.

Corbett, C., C. Hill, and A. Rose. 2008. Where the girls are: The facts about gender equity in education. Washington: American Association of University Women.

Davidson, M., and G. McKinney. 2001, January. Quantitative reasoning: An overview. Dialogue: A forum for the discussion of teaching, learning, and assessment 8:1-11. Office of Institutional Assessment and Teaching, Western Washington University. Accessed May 25, 2014 at http://www.uwyo.edu/smtc/_files/docs/projects/qr\%20stem/qr\%20resources/ quantitative\%20reasoning\%20an\%20overview.htm

Faust, M. W., M. H. Ashcraft, and D. E. Fleck. 1996. Mathematics anxiety effects in simple and complex addition. Mathematical Cognition 2: 25-62. http://dx.doi.org/10.1080/135467996387534

Fennema, E. 1989. The study of affect and mathematics: A proposed generic model for research. In Affect and mathematical problem solving: A new perspective, ed. D. B. McLeod and V. M. Adams, 205-219. New York: Springer-Verlag. http://dx.doi.org/10.1007/978-1-4612-3614-6_14

Fennema, E. and J. A. Sherman. 1976. Fennema-Sherman Mathematics Attitudes Scales: Instruments designed to measure attitudes toward the learning of mathematics by males and females. Catalog of Selected Documents in Psychology 6(1): 31.

Gregorc, A.F. 1979. Learning/teaching styles: Their nature and effects. In Student Learning Styles: Diagnosing And Prescribing Programs, ed. J. W. Keefe, 19-26. Reston, VA: National Association of Secondary School Principals.

Hembree, R. 1990. The nature, effects, and relief of mathematics anxiety. Journal for Research in Mathematics Education 21: 33-46. http://dx.doi.org/10.2307/749455

Kalder, R.S., and Lesik, S.A. 2011. A classification of attitudes and beliefs towards mathematics for secondary mathematics pre-service teachers and elementary pre-service teachers: An exploratory study using latent class analysis. Issues in the Undergraduate Mathematics Preparation of School Teachers: The Journal: Article 5.

Kilpatrick, J., J. Swafford, and B. Findell. 2001. Adding it up: Helping students learn mathematics. Washington, DC: National Academy Press. 
Leder, G. C., G. Rowley and C. Brew. 1999. Gender differences in mathematics achievement: Here today and gone tomorrow? In International Comparisons in Mathematics: The State of the Art, ed. G. Kaiser, E. Luna, I. Huntley, 213224. London: Falmer Press.

Liu, M., P. Hsieh, Y. Cho, and D. Schaallert. 2006. Middle school students' selfefficacy, attitudes, and achievement in a computer-enhanced problem-based learning environment. Journal of Interactive Learning Research 17(3): 225242.

Ma, X. 1999. A meta-analysis of the relationship between anxiety toward mathematics and achievement in mathematics. Journal for Research in Mathematics Education 30: 520-541. http://dx.doi.org/10.2307/749772

— , and W. Johnson. 2008. Mathematics as the critical filter: Curricular effects on gendered career choices. In: Gender and occupational outcomes: Longitudinal assessments of individual, social, and cultural influence, ed. $\mathrm{H}$. M. G. Watt and J. S. Eccles, 55-83. Washington, DC: American Psychological Association.

Mackay, B. \& S. Wismath. 2012. Quantitative courses in a liberal education program: A case study. Journal of General Education 61(4): 314-322.

Madison, B. L. and S. W. Dingman. 2010. Quantitative reasoning in the contemporary world 2: Focus questions for the numeracy community. Numeracy 3(2), Art. 5.

Maloney, E. A., D. Ansari, and J. A. Fugelsang. 2010. The effect of mathematics anxiety on the processing of numerical magnitude. Quarterly Journal of Experimental Psychology 64: 10-16. http://dx.doi.org/10.1080/17470218.2010.533278

Maloney, E. A., E. F. Risko, D. Ansari, and J. Fugelsang. 2010. Mathematics anxiety affects counting but not subitizing during visual enumeration. Cognition 114: 293-297. http://dx.doi.org/10.1016/j.cognition.2009.09.013

Mathematics Association of America. 2014. Quantitative reasoning for college graduates: A complement to the standards, accessed May 2014 at http://www.maa.org/programs/faculty-and-departments/curriculumdepartment-guidelines-recommendations/quantitative-literacy/quantitativereasoning-college-graduates

Moore, A. M, and M. H. Ashcraft. 2012. Math anxiety, Encyclopedia of language and literature development, published online 2012-04-05 21:32:36.

Murray, T.S, Y. Clermont, and M. Binkley. 2005. Measuring adult literacy and life skills: New frameworks for assessment. Statistics Canada, Catalogue \# 89-552-MIE no. 13.

Richardson, F. C. and R. M. Suinn. 1972. The Mathematics Anxiety Rating Scale: Psychometric data. Journal of Counseling Psychology 19: 551-554. http://dx.doi.org/10.1037/h0033456 
Sadker, M., and D. M. Sadker. 1994. Failing at fairness: How America's schools cheat girls. New York: Scribner.

Schiebinger, L. 2001. Has feminism changed science? Cambridge, MA: Harvard University Press.

Sells, L.W. 1978. Mathematics - a critical filter. Science Teacher 45: 28-29.

Simpson, C. 1999. Quantitative reasoning (QR) progress report. Bellingham, Washington: Office of Institutional Research and Resource Planning, Western Washington University.

Stevens, T., A. Olivárez, Jr., W. Lan, and M. K. Tallent-Runnels. 2004. The role of mathematics self-efficacy and motivation in mathematics performance: Issues across ethnicity, Journal of Educational Research 97: 208-221. http://dx.doi.org/10.3200/JOER.97.4.208-222

Tapia, M. and G. E. Marsh. 2004. An instrument to measure mathematics attitudes. Academic Exchange Quarterly 8(2): 16--21.

Taylor, P. J., G. C. Leder, G. H. Pollard, and W. J. Atkins. 1996. Gender differences in mathematics: Trends in performance. Psychological Reports 78: 3-17. http://dx.doi.org/10.2466/pr0.1996.78.1.3

Zeldin, A. and J. Pajares, J. 2000. Against the odds: Self-efficacy beliefs of women in mathematical, scientific, and technological careers. American Educational Research Journal 37(1): 215-246. http://dx.doi.org/10.3102/00028312037001215 


\section{SURVEY ITEMS USED:}

1. Mathematics classes are stressful for me.

2. I'm one of those people who just doesn't understand mathematics.

3. Studying mathematics poses no problem for me.

4. When faced with a new mathematics problem, I know that I will eventually be able to find a solution.

5. Whenever I am given a mathematics question to do, I do not know how to get started.

6. I often admit to people that I am not good at mathematics.

7. I am proud of my abilities in mathematics.

8. I never do well academically in a mathematics course.

9. Mathematics is used by most people everyday.

10. Knowledge of mathematics is important to future success in life.

11. Having a background in mathematics will be useful regardless of whether I use it directly in the future or not.

12. Understanding mathematics is not really required once a person leaves school.

13. Other than Science, Mathematics is unrelated to any other subject area.

14. Mathematics is merely a set of rules and procedures that need to be memorized.

15. Mathematics classes are interesting and intellectually stimulating.

16. Mathematics requires no creativity.

17. Mathematics class is the most enjoyable class in my timetable.

18. Mathematics is something to be endured rather than enjoyed.

19. Given the choice to do challenging mathematics problems/ puzzles or to do a writing assignment, I would prefer to work on the mathematics problems/ puzzles. 20. There is no place in mathematics for discussion- you are either right or wrong. 21. I enjoy explaining mathematics to others.

22. Once I have the minimum requirements in mathematics to graduate, I will not take another course in this subject.

23. I would take mathematics courses as electives in my program.

24. I am interested in taking mathematics courses in areas beyond basic algebra and geometry.

25. I would recommend taking mathematics courses to my friends.

26. Getting the answer to a mathematics question is more important than the methods used to get there. 